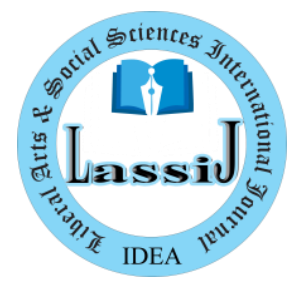

ISSN: 2664-8148 (Online)

Liberal Arts and Social Sciences

International Journal (LASSIJ)

https://doi.org/10.47264/idea.lassij/2.2.5

Vol. 2, No. 2, (July-December) 2018, 42-49

https://www.ideapublishers.org/lassij

\title{
Relationship of Biometric Attendance System with Performance, Job Related Stress and Satisfaction of University Teachers in Pakistan
}

\author{
Abid Ali $^{1}$, Javed Mustafa ${ }^{2 *}$ and Ihsan Ullah Khan ${ }^{1-3}$ \\ 1. Department of Sociology, University of Peshawar, Peshawar, Pakistan. \\ 2. Department of Education, Khushal Khan Khattak University, Karak, Pakistan. \\ 3. Department of Criminology, Law \& Justice, University of Illinois, Chicago, USA.
}

\begin{abstract}
The aim of this study is to dig-out the impact of biometric attendance on teachers' performance at Hazara University. A self-administered structured questionnaire is developed for data collection. A sample of 150 employees are chosen from the targeted population through stratified random sampling. The collected data is collated, coded, and punched in the SPSS for descriptive and inferential analysis. The results point out that $67 \%$ of those informants are male, while $33 \%$ are females. The highest number, $58 \%$ of employees are in Grade-18, and only 5\% employees are in Grade- 21 . Further, it shows that $88 \%$ participants are agreed to the installation of biometric attendance system. However, $87 \%$ respondents agreed that biometric system ensures teachers attendance on time. Moreover, correlation analysis results indicate that biometric system has a strong positive significant relationship with employees' attendance and employees' performance. But it has a significant negative relationship with job-related stress. Alongside, by independent sample T-test, gender differences are found that females are more in job-related stress than male due to the biometric system. The study concludes that biometric system has a high-level significant influence on the teachers' attendance schedule and their performance. Further, the study recommends the application of biometric attendance system in academia, it will, in turn, improve and ensure the performance level of employees.
\end{abstract}

Keywords: Technology, Biometric, Attendance, Performance, Job Stress, Job Satisfaction

\section{Introduction}

The knowledge industry has undergone through dramatic transformations, by the revolution of new-age technologies. A very promptly emerged and widespread technology always plays a vital role in the human performance. For the improvement of human's performance, biometric technology has been espoused by many institutions for enhancing their attendance system. In the epoch of quick technological progresses, academic organizations must to have lucrative and wellorganized systems to modernise and raise the academia performance. They need to demonstrate themselves by adaptation of higher quality services and greater productivity in remarkably 
competitive situation (Yuihotakaishi, 2011; Ullah, Mustafa, \& Badshah, 2017). The efficiency of an organization based on system for monitoring and assessing quality and regularity of the employees for growing the efficiency and effectiveness. On this background, biometric attendance system for staff in academic institutions has been introduced in current times to make the employees well-organized and task oriented (Hashim, 2011; Aqsa, Riaz, \& Saleem, 2017).

The aim of this study is to measure the impacts of novel technology on the teachers' performance. The remining manuscript has been arranged in four different sections. First section discussed the available secondary material pertaining to the topic of the study at local and international level. Second portion focuses on the nature of material/data collected and the methods used for collection of this data along with the techniques of analysis. Second last section is a detailed discussion, analysis, and findings of the study vis-à-vis the theoretical literature. Last section of the study has concluded the main findings of the analysis and discussion of the research.

\section{Literature Review}

Over the past several decades, learning institutions have experienced rapid transformations, by the revolution of modern technologies. A very quickly emerged and common technology, biometric attendance system (BAS) adopted by many institutions for tracking employees' attendance and time to improve their performance (Akinduyite, Adetunmbi, Olabode, \& Ibidunmoye, 2013). It's connecting people to their special human resource records that could precisely capture actual data by certifying that staffs come to the workplace at proper time and leave the duty place at the right time (Shehu \& Dika, 2011). Moreover, they feel the job satisfaction that their struggles are acknowledged through the balanced workload. Because employee attendance has a direct influence on the operational performance of an organization and crucial aspects of ensuring that the organization achieves their set operational performance levels (Ononiwu \& Okorafor, 2012).

The low attendance and unauthorized absenteeism are lingering concerns in many institutions but frequently those who are connected to educational and health care institutions. Employee identification is important in ensuring that the actual employee attends to duty. The government consumes millions of the financial budget each year on the formation of unique monitoring divisions to address the problem of low attendance and unauthorized absenteeism from workplaces, particularly academia and health care units, but they botched to acquire the preferred outcomes. Where the employees' identification is not done effectively, who are expected to be on duty may fail to report because their colleagues' sign for them if manual attendance registers are used instead of the biometric attendance system (Ali, 2015). This research study was conducted with the objective to investigate the role of biometric attendance system on teachers' performance and attendance at Hazara University, Mansehra.

A study has been conducted that many institutions adopted biometric attendance systems to increase the labour/employee work efficiency and workforce administration. In contrast to those manual procedures, biometric system of attendance is free from errors, accessible and greatly corrects (Activenanda, 2016). While previous studies have attempted to establish a relationship between biometric attendance management systems and an organization's performance (Akinduyite, Adetunmbi, Olabode, \& Ibidunmoye, 2013; Cupido, 2011; Shawl, 2013). Most of 
the empirical studies (Mulumba, 2012; Omobogo, 2015; Adewole, Adbulsalam, Babatunde, Shittu, \& Oloyede, 2014) have shown a more positive relationship of biometric attendance systems and organizational performance. Actual attendance scheduling in the place of work supports in increasing employee or workers' productivity, which leads to overhead cost saving that enhances an organization's operational performance (Ononiwu \& Okorafor, 2012).

A research study was conducted at Afe Babalola University, Nigeria to assess the performance of employees after installation of Biometric Attendance System (BAS). The findings show that it boosted work potential, the dedication of work among employees and provide a base to promote unbiased dedicated workers and have been observed working potential of employees. The boss can also be capable to recognize the areas of non-attendance in the office which can be used to reorganize of work. This technology regularized the employees, but their effort in their jobs remained unchanged and it may be at risk of exclusion. While it also observed that there are some challenges during the identification or the attendance process like time inaccuracy and lack of awareness that how to operate the machine (Afolalu, Tope-Oke, \& Atsadu, 2016). Simultaneously, another study shows that some fields gained discipline, punctuality, and efficiency, which simply has a positive effect on its uses. But at the same time some negative impacts were observed that BAS technology is one of the expensive on the economic point of view, secondly, it has been used for formality rather than performance. A research work argued that the system may be efficient both in educational institutions and offices to boost up the work, punctuality as well as work dedication (Gelb \& Clark, 2013).

\section{Method and Materials}

This study was quantitative in nature and conducted at Hazara University, Mansehra Khyber Pakhtunkhwa. The targeted participants of this study were the teaching faculty of the selected University. Data is collected through self-structured questionnaire, ranging from (1= Strongly Disagree; $5=$ Strongly Agree) from a sample of 150 respondents by stratified random sampling. Data is analysed and interpreted according to the objectivities of the study to draw some empirical results. The collected data has been punched and analysed through (SPSS) and the descriptive and inferential statistics are used to analyse the collected data. Descriptive statistics constituted frequencies; percentages are calculated for institutional data to describe the key features of the study. Inferential statistics is used which included correlation analyses to know about the relationship of predictor and outcome variables. While an independent Sample T-test is used to find the difference between both the genders about the job-related stress.

\section{Results and Discussion}

The table- 1 shows the personal information of the respondents in which $67 \%$ are male and $33 \%$ are female respondents. In the age set, $16 \%$ belong to $25-30,27 \%$ belong to age group $31-35,42 \%$ belong to the age group 36-40 and only $15 \%$ belong to the age group of above 40 . According to qualification, 24\% have an MA/MSc, while $15 \%$ are MPhil degree holders and $20 \%$ are $\mathrm{PhD}$ qualified. Moreover, in the on-campus and off-campus residency aspect, $34 \%$ are living inside the campus and $66 \%$ are from outside of the campus. In the categorization of the grades/scales, $58 \%$ have Grade-18, 21\% have Grade-19 and only 5\% are in Grade-21. 
Relationship of Biometric Attendance System with Performance, Job Related Stress and....

Table-01: Basic Demographic Information

\begin{tabular}{|l|l|c|c|}
\hline Description & Attributes & Frequency & Percentage \\
\hline \multirow{3}{*}{ Gender } & Male & 101 & 67 \\
\cline { 2 - 4 } & Female & 49 & 33 \\
\hline \multirow{4}{*}{$\begin{array}{l}\text { Rese of } \\
\text { Respondents }\end{array}$} & $25-30$ & 24 & 16 \\
\cline { 2 - 4 } & $31-35$ & 41 & 27.33 \\
\cline { 2 - 4 } & $36-40$ & 63 & 42 \\
\cline { 2 - 4 } & Above 40 & 22 & 14.66 \\
\hline \multirow{3}{*}{$\begin{array}{l}\text { Residency } \\
\text { Gradification }\end{array}$} & MA/MSc & 36 & 24 \\
\cline { 2 - 4 } Employee & MPhil & 84 & 56 \\
\cline { 2 - 4 } & PhD & 30 & 20 \\
\cline { 2 - 4 } & Campus side & 51 & 66 \\
\hline & Out of campus & 99 & 58 \\
\cline { 2 - 4 } & Grade-18 & 31 & 21 \\
\cline { 2 - 4 } & Grade-19 & 24 & 16 \\
\cline { 2 - 4 } & Grade-20 & 8 & 5 \\
\hline
\end{tabular}

The table- 2 shows that majority i.e. $88 \%$ respondents are agreed, and a little number i.e. $2 \%$ respondents are strongly disagreed and are not in favour of biometric attendance system. While $44 \%$ agreed that biometric attendance is useful for employees' regularity and the very low ratio of the employees have a negative response. Besides, majority i.e., 56\% respondents take biometric attendance system positive and helpful for ensuring timely attendance. Majority of them i.e., $46 \%$ are agreed that with the installation of biometric attendance system, the irregular and habitual absenter employees can be controlled. Now if the attendance piece is missed, all the attendance record will be vanished. Along with this, the $32 \%$ respondents have agreed that biometric system is the only solution for employees' regularity and 38\% agreed that biometric system eases the management work about employees' attendance. Simultaneously, the results show that 59\% informants believed that biometric system increases the employees' stress about the time and attendance, and $62 \%$ agree that it negatively affects the employees' motivation towards the job and leads to unnecessary mistrust.

The majority i.e., $48 \%$ of the respondents had the opinion that biometric attendance system causes to cut off the employees from social relations and social activities. The results show that $42 \%$ of the respondents are strongly disagree with the statement that it increases the job satisfaction and hence they are not satisfied with their job due to the installation of the biometric system. While $39 \%$ of the respondents are agree that they receive recognition and acknowledgement for the job as well done. So, most employees $49 \%$ are agree and prefer to work in this university. Further, $47 \%$ respondents are agreed that biometric attendance increases the work efficiency of employees. They are regular in attending the workplace because of the installation of Biometric system. Similarly, $87 \%$ of the respondents are agreed that biometric system improves the attendance of employees and become easier and more accurate. 
Table-2: Descriptive Analysis of Bioinformatics Attendance System and Performance Aspects

\begin{tabular}{|c|c|c|c|c|c|c|c|}
\hline \multicolumn{2}{|c|}{ Description } & SDA & DA & $\mathrm{N}$ & A & SA & M \\
\hline \multirow{3}{*}{ 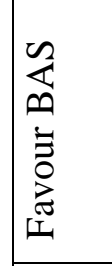 } & $\begin{array}{l}\text { In favour of biometric attendance } \\
\text { system }\end{array}$ & $3 / 2$ & $6 / 4$ & $5 / 3.33$ & $131 / 88$ & $5 / 3.33$ & \multirow{3}{*}{3.98} \\
\hline & Biometric attendance is useful & $10 / 6.66$ & $29 / 19.33$ & $12 / 8$ & $66 / 44$ & $33 / 22$ & \\
\hline & $\begin{array}{l}\text { Employees take biometric } \\
\text { attendance positive }\end{array}$ & $11 / 7.33$ & $21 / 14$ & $22 / 14.6$ & $56 / 37.3$ & $40 / 26.6$ & \\
\hline \multirow{3}{*}{ 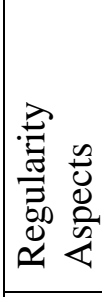 } & $\begin{array}{l}\text { Helps to control irregular } \\
\text { employees }\end{array}$ & $8 / 5.3$ & $11 / 7.3$ & $14 / 9.3$ & $68 / 45.3$ & $49 / 32.6$ & \multirow{3}{*}{3.87} \\
\hline & $\begin{array}{l}\text { Only solution for employee's } \\
\text { regularity }\end{array}$ & $11 / 7.3$ & $23 / 15.3$ & $31 / 20.6$ & $48 / 32$ & $37 / 24.6$ & \\
\hline & $\begin{array}{l}\text { Eases the management work about } \\
\text { attendance }\end{array}$ & $7 / 4.6$ & $12 / 8$ & $26 / 17$ & $57 / 38$ & $48 / 32$ & \\
\hline \multirow{3}{*}{ 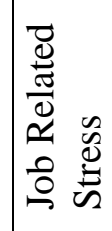 } & Increases the employee stress & $7 / 4.6$ & $5 / 3.3$ & $19 / 12.6$ & $31 / 20.6$ & $88 / 58.6$ & \multirow{3}{*}{3.76} \\
\hline & $\begin{array}{l}\text { Negativity effect the employee's } \\
\text { motivation }\end{array}$ & $6 / 4$ & $12 / 8$ & $16 / 10.6$ & $23 / 15$ & $93 / 62$ & \\
\hline & Cut off from social activities & $23 / 15.3$ & $16 / 10.6$ & $6 / 4$ & $43 / 28.6$ & $72 / 48$ & \\
\hline \multirow{3}{*}{ 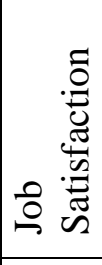 } & Increases the job satisfaction & $64 / 42.6$ & $46 / 30.6$ & $21 / 14$ & $11 / 7.3$ & $8 / 5.3$ & \multirow{3}{*}{3.57} \\
\hline & $\begin{array}{l}\text { Receive recognition for a job well } \\
\text { done }\end{array}$ & 16/10.6 & $10 / 6.6$ & $22 / 14.6$ & $43 / 28.6$ & $59 / 39.3$ & \\
\hline & $\begin{array}{l}\text { I feel good about working at this } \\
\text { university }\end{array}$ & $14 / 9.3$ & $24 / 16$ & $9 / 6$ & $73 / 48.6$ & $30 / 20$ & \\
\hline \multirow{2}{*}{ 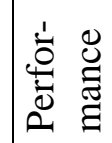 } & Increases the work efficiency & $22 / 14.6$ & $19 / 12.6$ & $11 / 7.3$ & $67 / 44.6$ & $31 / 20.6$ & \multirow[b]{2}{*}{3.68} \\
\hline & BAS improves the attendance & $4 / 2.66$ & $6 / 4$ & $2 / 1.33$ & $130 / 87$ & $8 / 5.33$ & \\
\hline
\end{tabular}

The table- 3 shows that there is a significant strong positive relationship ( $r=0.76, p=0.000$ ) between BAS and employees in favour of it at the 0.005 level of significance. While the participants believed BAS can regularize the employees and a source of proper check and balance. Mostly the attendance structure that are used in academic institutions are still transcribed on a part of paper and risk of losing the attendance data is very high. A significant relationship $(\mathrm{r}=0.81, \mathrm{p}=0.000)$ founded between BAS and regularity aspects. Besides, BAS increases the employees' stress and a negative significant relationship

\begin{tabular}{|l|c|c|}
\hline Table-3: Correlation between BAS and Performance \\
\hline Performance & Pearson Correlation $(\mathrm{r})$ & Sig $(\mathrm{p})$ \\
\hline Favour of BAS & 0.76 & $0.000^{* *}$ \\
\hline Regularity Aspects & 0.81 & $0.000^{* *}$ \\
\hline Job Related Stress & -0.50 & $0.000^{* *}$ \\
\hline Job Satisfaction & 0.19 & 0.007 \\
\hline Performance Aspects & 0.72 & $0.005^{* *}$ \\
\hline
\end{tabular}

$* *$ Correlation is significant at 0.005 level of significance

is found $(\mathrm{r}=-0.51, \mathrm{p}=0.000)$ with job-related stress. Moreover, a weak and non-significant connection $(r=0.19 ; p=0.007)$ is found between BAS and employees' job satisfaction. While, BAS 
improves the performance of the employees, a significant $(\mathrm{r}=0.72, \mathrm{p}=0.005)$ relationship is found between the BAS and employees' performance.

The table-4 group statistic shows an analysis of the sample size, mean and standard deviation. In the sample size, there are 101 male $($ Group=1) participants and they are an easy target of jobrelated stress with an average of 3.28 , with a standard deviation and standard error of the mean $1.121 \quad$ and 0.121 correspondingly. Alongside, there are 49 female respondents in $($ Group=2), and they are facing a job-related stress with

Table-4: Group Statistics

\begin{tabular}{|l|l|l|l|l|l|l|}
\hline \multirow{4}{*}{$\begin{array}{l}\text { Job Related } \\
\text { Stress }\end{array}$} & Group & Gender & $\mathrm{N}$ & Mean & Std. D & Std. E.M \\
\cline { 2 - 7 } & 1 & Male & 101 & 3.28 & 1.121 & 0.121 \\
\cline { 2 - 7 } & 2 & Female & 49 & 3.56 & 0.747 & 0.108 \\
\hline
\end{tabular}
an average of 3.56, standard deviation and standard error of the mean of 0.747 and 0.108 orderly.

The table-4.1 indicates the results of Independent Sample T-Test. It is used to find out the dissimilarity between the two groups. Applying T-test results are established on the significance level of Levene's Test for Equality of Variance. If level is higher than (0.05), then equal variance assumed are used, if significance level is less than (0.05) then equal variance not assumed are applied. Consequently, the level is .009 which is $>0.05$, so the equal variance assumed is applied. $\mathrm{T}$ value (-1.466) with (136) degree of freedom, it is significant at (0.148) level and both $\mathrm{T}$ test significance is dissimilar. Therefore, the results clarify that both genders are considerably dissimilar in respect to job-related stress. Additionally, by noticing the groups means and mean dissimilarities between both groups, females were facing more job-related stress $(M=3.56)$ as compared to the male group.

Table-4.1: Independent Sample T-Test

\begin{tabular}{|l|c|c|c|c|c|c|c|}
\hline \multicolumn{9}{|l|}{ Levene's Test of EV } & \multicolumn{7}{l|}{ T-Test for Equality of Means } \\
\hline Job-Related Stress & F & Sig & T & Df & 2-tailed sign & M.D & Std. E. D. \\
\hline Equal Variances Assumed & 7.168 & 0.009 & -1.466 & 136 & 0.148 & -0.266 & 0.182 \\
\hline Equal Variances not Assumed & & -1.640 & 126.13 & 0.103 & -0.266 & 0.162 \\
\hline
\end{tabular}

\section{Conclusion}

In a modern and rational society biometric attendance system introduces in various organisations for the operational performance. The purpose of the study has been to examine the impacts of biometric attendance on teacher performance at Hazara University, Mansehra. Based on the findings of the study, it is concluded that most of the faculty members are in the favour of biometric attendance system. There as a statistically significant influence of biometric attendance system on teacher performance and regularity aspects. Because BAS improvs the net performance of the institution due to reliability, efficiency, and capable of replacing the traditional manual system of 
attendance. Further, it has been found that there is negative significant relationship between BAS and job-related stress and non-statistically significant relationship with job satisfaction. It is concluded from the study that biometric attendance system provides open entrance to all employees' attendance data as well as easy checking of monthly attendance records. This system ensures the safety of employees' records; eliminates false attendance system, protects time as well as decreases the amount of work done by the manager in collecting of the employees' attendance data. This study recommends launching of a biometric attendance system or bio-card for employees to track the attendance record and ensure the performance of teachers and instructors in any higher education institution.

\section{References}

Activenanda, G. (2016). Biometric fingerprint time attendance system. Retrieved from, http://www.atss.in/biometric-time-attendance/

Adewole, K., Adbulsalam, S., Babatunde, R., Shittu, T., \& Oloyede, M. (2014). Development of finger biometric attendance system for non-academic staff in a tertiary institution. Computer Engineering and Intelligent Systems Review, 5(2), 555-567.

Afolalu, C. A., Tope-Oke, A., \& Atsadu, S. (2016). Towards an efficient biometric employee attendance system. International Journal of Research in Business Management, 7(4), 6578.

Akinduyite, C. O., Adetunmbi, A. O., Olabode, O. O., \& Ibidunmoye, E. O. (2013). Fingerprint based attendance management system. Journal of Computer Sciences and Applications, 1(5), 100-105.

Ali, Z. (2015). Impact of biometric attendance system on Khalid Bin Walid Park in Peshawar cantonment area KP. Daily Dawn. Retrieved from, https://www.dawn.com/news/1183764

Aqsa, K., Riaz, W., \& Saleem, Z. (2017). The effectiveness of games in English language learning at elementary level in government schools. Liberal Arts and Social Sciences International Journal (LASSIJ), 1(2), 12-23.

Cupido, H. (2011). The implementation of a time and attendance system at Stellenbosch municipality: A change management perspective masters project in public administration. University of Stellenbosch.

Gelb, A., \& Clark, J. (2013). Identification for development: The biometric revolution, Center for global department. Washington, D.C, United States of America.

Hashim, A. Y. (2011). An enduring relationship between biometric traits and security systems. International Journal of Research and Reviews in Information Security and Privacy, $1(1), 1-6$.

Mulumba, M. (2012). Biometric authentication systems and service delivery in healthcare sector in Kenya. Retrieved from, https://poseidon01.ssrn.com/delivery.php

Omobogo, R. M. (2015). Contemporary strategy analysis, (4 ${ }^{\text {th }}$ ed.). Oxford: Blackwell.

Ononiwu G. C., \& Okorafor, G. N. (2012). Radio frequency identification based attendance system with automatic door unit. Academic Research International, 2(2), 45-50.

Shawl, D. (2013). Biometric implementing into the healthcare industry increases the security for doctors, nurses, and patients. Journal of Computer Sciences \& Applications, 
$12(1), 22-32$.

Shehu, V., \& Dika, A. (2011). Using real time computer vision algorithms in automatic attendance management systems. Proceedings of the ITI 2010 32nd International Conference on Information Technology Interfaces, June 21-24, 2010, Cavtat, Croatia.

Ullah, K., Mustafa, J., \& Badshah, S. (2017). Gender-wise perception of graduate and undergraduate students about the quality of teaching. Liberal Arts and Social Sciences International Journal (LASSIJ), 1(1), 10-19.

Yuihotakaishi (2011). Attendance monitoring system using biometrics for security staff. Study Mode Inspiring. Retrieved from http://www.studymode.com/essays/AttendanceMonitoring-System-Using-BiometricsFor-732262.html. 